\title{
EL USO DE LA BARRA (/) \\ EN EL AMOR, LAS MUJERES Y LA VIDA, DE MARIO BENEDETTI
}

\section{THE USE OF THE FORWARD SLASH (/) \\ IN LOVE, WOMEN AND LIFE, BY MARIO BENEDETTI}

\author{
José Manuel Begines Hormigo \\ Universidad de Sevilla
}

Resumen: Mario Benedetti, encuadrado en la poética conversacional hispanoamericana, tiende a buscar un equilibrio entre la realización tradicional de sus versos y una realización próxima al registro lingüístico coloquial. Para conseguirlo, el poeta uruguayo, que abandona el uso de los signos de puntuación en su poesía con el fin de acercarla a la oralidad, se sirve de la barra (/) como elemento de comunicación con el lector. En la antología temática El amor, las mujeres y la vida, la barra desempeña una serie de funciones que van desde las meramente sintácticas hasta las propiamente métricas.

Palabras clave: Mario Benedetti, pausa, cesura, uso de la barra, poesía conversacional, El amor, las mujeres y la vida.

Abstract: Mario Benedetti, placed in the category of conversational Spanish-American poetry, tends to look for 
a balance between a more traditional writing of his verses and a style closely resembling colloquial language. To achieve this, the Uruguayan poet, who leaves aside the use of punctuation marks in his poetry in order to bring it closer to oral language, makes use of the forward slash $(/)$ as a means of communication with the reader. In the thematic anthology Love, Women and Life, the slash serves a number of functions ranging from the purely syntactic to the metric ones.

Keywords: Mario Benedetti, pause, caesura, use of the forward slash, conversational poetry, Love, Women and Life. 


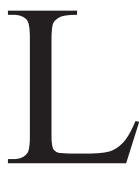

a diferencia fundamental entre el verso simple y el verso compuesto es que el segundo se puede dividir en hemistiquios. En los versos alejandrinos, que gozan de una amplia tradición en la literatura española, la cesura que divide ambos hemistiquios se sitúa tras la séptima sílaba. En los versos decasílabos compuestos, tras la quinta sílaba. En los versos dodecasílabos compuestos, con estructura simétrica, tras la sexta sílaba. Ningún lector de poesía tendrá problemas en seguir la lectura, y marcar bien el ritmo, de este tipo de versos.

Mayores problemas presentan los versos donde la cesura, que marca pautas métricas y repercute en el cómputo silábico, no es tan clara. El caso más evidente es el del verso libre. Algunas veces, señala Esteban Torre ${ }^{1}$, el verso libre no es más que el resultado de la unión de varios versos en una misma línea. De esta manera, propone entender el verso «ni el alba había pensado en la negra existencia de los malos cuchillos», de Rafael Alberti, como la unión de tres heptasílabos tradicionales: «ni el alba había pensado / en la negra existencia / de los malos cuchillos». La dificultad para la escansión del verso se encuentra cuando no es tan fácil reducir esas líneas a esquemas tradicionales o a pautas métricas. Por esa razón, concluye el profesor Torre, en esos casos concretos, «las fronteras entre la prosa y el verso son, en realidad, imprecisas y fluctuantes $»^{2}$.

No obstante, sin llegar a los extremos de la libertad absoluta, de la disolución de la diferencia entre el verso y la prosa, se pueden encontrar versos compuestos tradicionales donde el ritmo no es tan marcado como para permitir una lectura inequívoca o donde la distribución de los acentos introduce ciertas

${ }^{1}$ TORRE, Esteban: Métrica española comparada. Sevilla: Universidad, 2000, pp. 102 y ss.

${ }^{2}$ Ibid., p. 106. 
ambigüedades. Tal es el caso de los dodecasílabos del tipo «7+ $5 »$ o del tipo « $5+7 »$ que, en un poema en verso blanco, podrían escandirse de distinta manera, hasta el extremo de ser considerados endecasílabos; o al contrario, endecasílabos que podrían permitir una lectura con cesura y su transformación en verso dodecasílabo.

En el artículo «Endecasílabos con acento en $6^{\mathrm{a}}$ y $7^{\mathrm{a}}$ sílabas», el profesor Márquez Guerrero concluye que este tipo de versos, cuyo acento principal es dudoso, atesoran un gran valor estilístico porque, por un lado, armonizan con los endecasílabos comunes y porque, por otro lado, permiten una lectura como verso compuesto, bipartito, con pausa tras la $6^{\mathrm{a}}$ «no obligatoria sino optativa para el lector» ${ }^{3}$.

El profesor Márquez limita la posibilidad de considerar el verso endecasílabo como compuesto a los casos en que confluyen los acentos en $6^{\mathrm{a}}$ y $7^{\mathrm{a}}$ sílabas. Esteban Torre, por su parte, extiende la posibilidad de considerar como compuestos a los versos donde se suceden los acentos en $4^{\mathrm{a}}$ y $5^{\mathrm{a}}$, con pausa tras la cuarta sílaba e, incluso, a los versos donde ni siquiera existe ese choque acentual sino tan solo un acento en cuarta sobre monosílabo o palabra aguda. Sin embargo, para el profesor Torre, considerar el endecasílabo como un verso compuesto (del tipo $7+5$ o 5+7) constituiría la aplicación de los criterios de la métrica francesa a la española y supondría la supresión de la distinción entre versos simples y compuestos ${ }^{4}$.

Sirva como ejemplo de lo que viene diciéndose, el siguiente fragmento de «Elegía española (I)» de Luis Cernuda:

Háblame, madre;

Y al llamarte así, digo

Que ninguna mujer lo fue de nadie

Como tú lo eres mía.

Háblame, dime

Una sola palabra en estos días lentos.

En los días informes

\footnotetext{
${ }^{3}$ MÁrquez Guerrero, Miguel Ángel: «Endecasílabos con acentos en $6^{\mathrm{a}}$ y $7^{\mathrm{a}}$ sílabas». Rhythmica. Revista española de Métrica Comparada, 2012, X, pp. 128 y ss.

4 TORRE, Esteban: «¿Acentos contiguos en el verso español?». Rhythmica. Revista española de Métrica Comparada, 2014, XII, pp. 190 y ss.
} 
Que frente a ti se esgrimen

Como cuchillo amargo

Entre las manos de tus propios hijos.

No te alejes así, ensimismada

Bajo los largos velos cenicientos

Que nos niegan tus anchos ojos bellos. [...]

Contempla ahora a través de las lágrimas:

Mira cuántos traidores,

Mira cuántos cobardes 5 .

Este poema combina versos de ritmo endecasilábico de diferente medida: pentasílabos, heptasílabos, eneasílabos, endecasílabos, dodecasílabos y alejandrinos. En ese contexto, algunos de los versos permiten una doble interpretación métrica. El verso «que ninguna mujer lo fue de nadie» va precedido por un pentasílabo (há-bla-me-má-dre) y un heptasílabo (yal-lla-már-teasi-dí-go) y sucedido de un heptasílabo (co-mo-tú-loe-res-mí-a) y un pentasílabo (há-bla-me-dí-me). En ese contexto, ese verso podría permitir una doble lectura: como un endecasílabo melódico (que-nin-gú-na-mu-jér-lo-fue-de-ná-die) o como un dodecasílabo del tipo 7+5 (que-nin-gú-na-mu-jér / lo-fué-de-ná-die). Ambas lecturas pueden considerarse igualmente válidas para mantener el ritmo endecasilábico del poema.

En el caso del verso «no te alejes así, ensimismada» también es posible una doble lectura. Sin embargo, parece más apropiada la consideración del verso como dodecasílabo puesto que, de no ser así, obligaría al lector, para conservar el ritmo endecasilábico, a pronunciar en sílabas distintas lo que en una pronunciación natural formaría parte de una misma sílaba. La escansión de estos versos, por lo tanto, quedaría del siguiente modo:

$$
\text { no-tea-le-jes-a-sí / en-si-mis-ma-da }(6+1 / 5)
$$

Distinto es el caso del verso «contempla ahora a través de las lágrimas», donde no es posible su lectura como un verso simple. Si se intenta hacer una lectura en que se conserven

${ }_{5}^{5}$ Cernuda, Luis: Las Nubes. Desolación de la Quimera. Madrid: Cátedra, 1999, p. 71. 
las 11 sílabas del endecasílabo, 12-1 en este caso, (con-témplaa-hó-raa-tra-vés-de-las-lá-gri-mas) el ritmo del verso y del poema se rompería, puesto que queda como acento principal la séptima sílaba (vés); por el contrario, si se pretende hacer una lectura donde se conserve el acento principal en la sexta sílaba, las sinalefas son forzadas y antinaturales (con-tém-plaaho-raatra-vés-de-las-lá-gri-mas) y el número de sílabas resultante sería 10 (11-1); un decasílabo, por tanto. Por consiguiente, la única realización posible de este verso, aquella a la que empuja el ritmo de los demás versos de la composición, es la que da como resultado un verso dodecasílabo:

\section{con-tém-plaa-hó-ra / a-tra-vés-de-las-lá-gri-mas (5 / 8-1)}

Jauralde Pou, en su Manual de métrica española, publicado en colaboración con Elena Varela y Pablo Moíno, se refiere a las variaciones que pueden experimentar las diferentes lecturas de un mismo verso o poema. Jauralde Pou concluye que «los versos permiten diferentes realizaciones o lecturas, pero que no todas son posibles sin transgredir normas métricas o prosódicas $\rangle^{6}$.

Este tipo de problemática no se presenta en poemas donde el ritmo es repetitivo y contundente y no deja lugar a la duda. «Sonatina» o "Sinfonía en gris mayor», de Rubén Darío, son ejemplos paradigmáticos de poemas donde se emplea un ritmo que conduce a los lectores a una única realización de la lectura de los versos. El ritmo envuelve la lectura y limita la libertad del lector, obligado a recibir el poema de una única forma.

En algunos poetas del siglo Xx, existe la tendencia de dejar libertad a los lectores en la interpretación o la lectura de los poemas, permitiéndose múltiples lecturas. Esto se consigue, muchas veces, suprimiendo la puntuación. La obra Vida y leyenda del jinete eléctrico, con la que reconocido poeta Joaquín Pérez Azaústre obtuvo el premio Jaime Gil de Biedma, en su convocatoria de 2013, puede servir como ejemplo. En este libro, escrito sin signos de puntuación y sin mayúsculas, Pérez Azaústre se sirve, en muchos de sus poemas, de un ritmo tradicional que el

${ }^{6}$ Jauralde Pou, Pablo, Varela, Elena y Moíno, Pablo: Manual de métrica española. Madrid: Castalia, 2005, pp. 50-51. 
lector debe descubrir. Escandimos, a continuación un fragmento del poema $20^{7}$ :
una almendra en el labio nácar del sol latente
$7 / 7$
con el pulso acatado en su quieta sordina
$7 / 7$
cómo va a disentir ninguna eternidad de su esquiva hipoteca
$6+1 / 6+1 / 7$
sin sanidad ni estigmas que llevarse a los ojos vamos a perdurar
$7 / 7 / 6+1$
de qué nos servirá la representación con su estricta agonía
$6+1 / 6+1 / 7$
hay que legalizar el cuarzo transitorio de todos los preámbulos
$6+1 / 7 / 8-1$
y tocar madre el agua sin paños ni alaridos
$7 / 7$

Con todo esto, se quiere evidenciar que, en algunas ocasiones $y$, sobre todo, para lectores poco avezados en la lectura de poesía y en el conocimiento de la métrica, es necesario el empleo de un elemento orientativo que sirva para situar rítmicamente al lector sobre el poema.

En 1996, Mario Benedetti publica El amor, las mujeres y la vida, en la editorial Visor. Este libro es una antología de poemas amorosos «que se fue haciendo solo en los últimos cincuenta años» ${ }^{8}$, según dice el autor en el prólogo. Es llamativo en este libro, en cuanto a la métrica se refiere, el empleo de la barra (/). Desde los primeros poemas hasta los últimos, Benedetti experimenta una evolución que lo lleva, por un lado, a abandonar los signos de puntuación tradicionales, y a utilizar la barra con diferentes valores, $y$, por otro, a ceñirse cada vez más a los patrones métricos tradicionales.

Según la Ortografía de la lengua española, de la Real Academia de la Lengua, en su edición de 2010, la barra (/) pertenecería al grupo de los signos auxiliares, que se definen por contraposición a los signos diacríticos y de puntuación y que cumplen variadas funciones ${ }^{9}$. Los usos más importantes, tal y como recoge la Real Academia son los siguientes ${ }^{10}$ :

-Como signo abreviativo: c/ en lugar de calle.

7 PÉrez Azaústre, Joaquín: Vida y leyenda del jinete eléctrico. Madrid: Visor Libros, 2013, pp. 47-48.

${ }^{8}$ Benedetti, Mario: El amor, las mujeres y la vida. Poemas de amor. Madrid: Visor Libros, 2007, p. 10. En adelante se citará por esta edición, indicando en el cuerpo del artículo, entre paréntesis, las páginas correspondientes.

9 RAE: Ortografia de la Lengua española. Madrid: Espasa Calpe, 2010, p. 278.

${ }^{10}$ Ibid., pp. 424 y ss. 
-Como signo indicador de final de línea:

-Para separar versos

-Para señalar el cambio de líneas en el original, cuando se transcriben portadas o colofones de textos antiguos. -En obras de ortografía.

-Como signo de unión o relación entre palabras o elementos, igual que el guion:

-Sustituyendo preposiciones $(\mathrm{km} / \mathrm{h})$

-Indicando opciones en una disyunción (querido/a)

-Otros usos:

- Para separar día, mes y año.

-Para señalar los subdominios jerárquicos en direcciones electrónicas

-Como signo de división, en Matemáticas.

-Como signo para la representación de los fonemas, en Lingüística.

Nada se dice, sin embargo, del uso tan habitual que se hace de la barra en los estudios sobre métrica, donde sirve para representar la cesura. Según la Ortografía de la lengua española, sería la doble barra vertical o pleca doble (\|) el signo que, en la edición de textos, sirve para señalar la cesura o pausa interior del verso ${ }^{11}$. No se atiende, por tanto, al uso métrico que se hace de la barra como demarcador de hemistiquios en la escansión de los versos.

Naturalmente, Mario Benedetti no está escandiendo versos y por eso, precisamente, llama la atención que la barra se haya convertido en el único signo ortográfico, además de los signos de interrogación o de exclamación, que emplea el uruguayo en sus poemas cuando decide abandonar definitivamente los signos convencionales $^{12}$. En una ocasión, Benedetti utiliza la barra de una manera ortodoxa, para marcar una disyunción: «al cabo de cuatro horas y/o lustros» (p. 154). Pero en el resto de los casos,

"I Ibid., p. 429.

12 "Por lo que respecta al empleo de la vírgula, será en Cotidianas (1978-1979) cuando por primera vez utilice este recurso, coexistiendo con los espacios en blanco, y con las mismas funciones que estos, a partir de este poemario» (IBÁNEZ QuINTANA, Jaime: La obra poética de Mario Benedetti (1948-1985). Tesis doctoral. Servicio de Publicaciones de la Universidad de Burgos, 2004, p. 371). 
es un uso peculiar que merece ser atendido, analizado y del que se pueden obtener una serie de consecuencias métricas.

Hay que distinguir entre pausa y cesura. Las pausas, según el profesor Torre, son interrupciones breves e intermitentes que «están motivadas por la sintaxis, por el deseo de destacar el sentido o simplemente por la necesidad de respirar» ${ }^{13}$ y pueden, o no, coincidir con el final del verso o del hemistiquio. Frente a estas pausas, existen otras, continúa el profesor Torre, que sí tienen un carácter métrico y rítmico: la pausa final del verso y la cesura, al final del hemistiquio. Tanto la pausa final de verso como la cesura llevan aparejadas una serie de consecuencias métricas: la imposibilidad, salvo excepciones, de que se produzcan sinalefas y la equivalencia métrica de terminaciones agudas, llanas y esdrújulas.

Isabel Paraíso, por su parte, distingue entre pausas variables y pausas fijas. Las primeras son «fortuitas, motivadas por el sentido de cada línea poética» mientras que las segundas, las interesantes según la profesora Paraíso, «son estructurales, necesarias para la armonía y la configuración rítmica de los versos $\rangle^{14}$.

Efectivamente, en El amor, las mujeres y la vida de Benedetti, interesa, fundamentalmente, hacer una aproximación al uso de la barra como elemento demarcador, como señal para indicar dónde se encuentra la pausa estructural; sin embargo, y al mismo tiempo, es interesante prestar atención al empleo que Benedetti hace de la barra con otro valores, con otras intenciones comunicativas.

El poeta uruguayo abandona el empleo de los signos de puntuación a partir de su primer libro de éxito, Poemas de la oficina, que fue publicado en 1956. De manera que, en palabras de Carmen Alemany Bay, «sus poemas se liberarán de signos de puntuación, otorgando al texto mayor libertad y más capacidad de lecturas interpretativas $\rangle^{15}$. Esta libertad interpretativa del sentido del poema, a la que alude Alemany, se complementa con la libertad rítmica en la realización de alguno de sus versos. No

\footnotetext{
13 Torre, Esteban: Métrica española, cit., pp. 66 y ss.

14 Paraíso, Isabel: La métrica española en su contexto románico. Madrid: Arco/Libros, 2000 , p. 96.

15 Alemany Bay, Carmen: Mario Benedetti. Madrid: Eneida, 2000, p. 22.
} 
obstante, no se debe pensar, puesto que Benedetti, en El amor, las mujeres y la vida, utiliza, mayoritariamente, versos de ritmo endecasilábico, que la libertad para la interpretación métrica y rítmica del verso es absoluta. Si se tiene en cuenta la distinción de Roman Jakobson entre «ejemplo de verso» y «modelo de verso» ${ }^{16}$, se podría concluir que el ejemplo de algunos de los versos del uruguayo permite varias realizaciones, pero no cualquier realización ${ }^{17}$.

Al mismo tiempo que se despoja de los signos de puntuación para permitir al lector leer e interpretar su obra con mayor libertad, Benedetti, según Alemany Bay, se inscribe en ese grupo de escritores que, como Fernández Retamar, José Emilio Pacheco, Juan Gelman o Ernesto Cardenal, buscan siempre mantener una relación directa con el lector, en continuo diálogo con él, de manera que «tienen siempre presente al lector y reclaman a un interlocutor lo más activo posible» ${ }^{18}$. Esa comunicación con el lector, esa consideración del lector como un «lector-mi-prójimo» empuja a Benedetti hacia un estilo particular, identificado en ocasiones con el lenguaje coloquial, con una sintaxis sencilla y basada en estructuras paralelísticas, y lo empuja, también, a orientar a ese lector amigo, a ese lector prójimo, en el ritmo de sus poemas, en la lectura adecuada de sus versos. Para conseguirlo, recurre a la barra, que desempeña, como se verá a continuación, diferentes funciones. Por lo tanto, Benedetti libera al lector de la rigidez interpretativa que imponen los signos de puntuación y, al mismo tiempo, lo dirige en la realización métrica a través de hábitos propios del registro coloquial y a través de la barra.

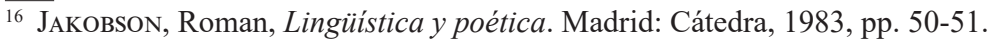

17 En este sentido, Domínguez Caparrós, a propósito de las opiniones de Julio Saavedra respecto a la variedad de interpretaciones rítmica que permiten los versos, sostiene que la libertad métrica o rítmica en la ejecución del verso no puede ignorar ni a su ejemplo ni a su modelo de verso: «Es obvio que Julio Saavedra Molina está asimilando el verso a lo que es cada ejemplo de ejecución, pero el hecho de que admita dos o más lecturas demuestra que el verso no es tampoco «la creación fugaz» solamente, sino que tiene que haber ciertas constantes que justifican esa variedad de ejecución. Y esas constantes vienen dadas tanto por el modelo como por el ejemplo de verso en cuestión» (Domínguez CAPARRós, José: Métrica y Poética. Bases para la fundamentación de la métrica en la teoría literaria moderna. Madrid: UNED, 2010, p. 85).

18 Alemany Bay, Carmen: Mario Benedetti, cit., p. 12. 
Para llevar a cabo el análisis, es interesante partir de la clasificación de versos que establece Jauralde Pou, según la calidad de las pausas. Jauralde Pou distingue entre versos cortos donde no hay posibilidad de que exista una pausa o una cesura, puesto que tienen un desarrollo unitario, y versos largos o complejos, de arte mayor, de doce o más sílabas, que se parten y dan lugar a semiversos o hemistiquios. Entre un tipo y otro, sitúa el autor los eneasílabos, los decasílabos y los endecasílabos, que permiten una distribución en hemistiquios o, por el contrario, una distribución unitaria donde existen pausas que no tienen el carácter de cesura o pausa versal ${ }^{19}$.

\section{Versos de hasta ocho sílabas}

\subsection{La barra como signo de puntuación, al final o en el interior de un verso}

En los versos de arte menor, Benedetti utiliza la barra con el objetivo de marcar una pausa breve, y no una cesura. Las barras delimitan estructuras sintácticas, de manera que están más relacionadas con los signos de puntuación tradicionales que con elementos de carácter métrico.

En el poema «Mujer de Lot» (p. 174), escrito en octosílabos, la barra hace las veces de una coma, uniendo sintagmas que realizan la misma función («con audacia / sin alertas», «lentamente / lentamente») o aislando el vocativo («mujer estatua / tu historia», «mujer estatua / por suerte», «mujer de lot / te prohíbo», «mujer otra / diferente»). En todos estos casos, el octosílabo se realiza como verso unitario que, naturalmente, no permite la cesura $y$, por lo tanto, la barra no tiene ningún efecto métrico, más allá del efecto prosódico propio de las comas.

Un caso bastante ilustrativo es el que puede encontrarse en el poema «Semáforos» (p. 159). El texto se organiza como una enumeración de realidades que evocan el color rojo y de otras realidades que evocan el color verde. En un momento de la enumeración, Benedetti necesita marcar la dependencia sintáctica de los elementos que aparecen en el verso y, por eso, se ve impelido a emplear la barra:

$\overline{19}$ JaUralde Pou, Pablo et alii: Manual de métrica..., cit., pp. 74-75. 


\author{
del loro de flaubert \\ de cezanne / de sillanpää \\ de juncos / de lisboa \\ del manto de los sueños
}

Sin el empleo de las barras, el lector puede entender que «de lisboa» complementa a juncos y no al adjetivo verde que aparece versos atrás: «verde de hoja y rocío». En el verso «del manto de los sueños», por el contrario, la ausencia de la barra indica que «de los sueños» complementa a «manto».

Pueden encontrarse diferentes ejemplos donde se repite este mismo uso, como en el poema «Triángulo» (p. 140):

\title{
y en ese territorio \\ buscarlos / dar con ellos sorprenderlos
}

En otras ocasiones, el poeta uruguayo utiliza la barra al final del verso, coincidiendo con la pausa versal. Es innecesario, por tanto, ese empleo, puesto que cualquier lector habituado a leer poesía sabe de la importancia de la pausa versal para el mantenimiento del ritmo del poema. Si Benedetti utiliza aquí la barra es porque quiere señalar que algo es diferente en ese final, que existe algún tipo de anomalía. En el poema "Medios de comunicación» (p. 129), por ejemplo, la barra equivale a un punto. Benedetti, por tanto, atribuye a la barra los usos propios de los signos de puntuación:
y llegó desde mí para decirte que están el río el girasol la estrella rodando sin apuro $/$
el futuro se acerca a conocerte y llegó desde mí para decirte

En el mismo sentido, Benedetti, en «Hablo de tu soledad» (p. 147), utiliza la barra como si fuera un guion o un paréntesis:

pero sucede que /

dijo calmosamente la mengana /

si tu bendita soledad

se funde con la mía 
Es destacable, en el último ejemplo, que uno de los versos termine en una categoría gramatical sin acento. En este caso, el poeta recuerda la necesidad de hacer una pausa que otorgue relevancia acentual a la conjunción, de manera que obliga al lector a detenerse y a marcar con mayor intensidad el ritmo del verso.

\subsection{La barra entre dos acentos contiguos}

Según afirma Esteban Torre, no pueden existir, en el verso español, acentos contiguos. Cuando dos sílabas tónicas entran en contacto en un verso, «una de ellas, la que ocupa la posición marcada por el acento rítmico o metarrítmico, es la que posee la más alta intensidad acústica, es decir, ese latido rítmico que llamamos acento» ${ }^{20}$. Efectivamente, de una forma que podría llamarse natural, el hablante tiende a dar relevancia acentual a una de esas sílabas en contacto y a establecer unos mecanismos de compensación, como el desplazamiento o la eliminación del acento de menor intensidad, para conservar la eufonía.

Benedetti, cuya obra puede encasillarse en la poesía conversacional que, en muchas ocasiones, trata de imitar las inflexiones, los énfasis y el orden sintáctico propios del habla coloquial, procura que el registro formal de la poesía, o la consideración del verso como una unidad rítmica, no impidan al lector alejarse de una lectura espontánea, dramática o enfática ${ }^{21}$.

En el verso «y vos / sos mi utopía», del poema «Utopías» (p. 137), el pronombre «vos» y el verbo «sos» están acentuados. Existen, por lo tanto, dos sílabas tónicas contiguas. Dependerá del lector que el verso tenga un ritmo binario (con acentos en las sílabas vos, miu y pí) o ternario (con acentos en las sílabas sos y pí). Benedetti se inclina por una lectura enfática en la que el tú de la amada se impone al verbo copulativo, mero nexo de unión entre el tú y lo que representa, entre el tú y la utopía.

Gracias al empleo de la barra, el lector, que asume como algo extraño ese uso y que, por lo tanto, se siente obligado a tener en cuenta la barra y a adaptar su lectura a esa aparición, hace una pausa tras «vos», de manera que se otorga un mayor peso

${ }^{20}$ TORre, Esteban: «Acentos contiguos...», cit., p. 194.

${ }^{21}$ Cfr. Alemany Bay, Carmen: Poética coloquial hispanoamericana. Alicante: Universidad, 1997. 
acentual al pronombre que al verbo, cuyo acento sufre un desplazamiento.

Sintácticamente, no se puede poner una coma entre un sujeto y su verbo. Tal vez este sea uno de los motivos por los que, al uruguayo, no le sirven ya los signos de puntuación tradicionales y los abandona. Con la barra, que unas veces adquiere el valor de un signo de puntuación y otras el valor de un elemento métrico o rítmico, el poeta puede dirigir, u orientar, de una forma más eficaz la lectura de sus versos, puede conseguir que sus lectores se aproximen a los patrones rítmicos con que imaginó sus versos, puede conseguir que el pronombre personal imponga la fuerza acentual que, por lo general, posee el verbo.

\subsection{La barra como marca de dialefa}

Interesante es el uso que Benedetti hace de la barra en el poema «Almohadas» (p. 168). Este poema, de 28 versos, está escrito, por completo, en heptasílabos, salvo un verso que funciona como bisagra en mitad del poema, en el verso decimocuarto. Ahí se rompe el ritmo. La inercia del lector lo lleva a hacer una sinalefa y seguir leyendo el verso como heptasílabo, pero Benedetti quiebra el poema y la inercia del lector. El verso en cuestión es el siguiente: «es la almohada / es ella».

La escansión de este verso puede resolverse de varias formas. Si no se atiende a la barra, podría decirse que este verso es un heptasílabo: és-laal-mo-há-daes-é-lla.

Pero Benedetti parece preferir una realización más coloquial del verso, en un registro menos formal, que atienda al paralelismo sintáctico que se establece entre las dos oraciones y haciendo, por lo tanto, una pausa entre «almohada» y «es» lo suficientemente larga como para que ambas vocales en contacto no formen una única sílaba.

Todo el poema está escrito en versos de siete sílabas y parece un contrasentido que Benedetti quiebre el ritmo de esa forma. Si se respeta la dialefa, la escansión puede ser de dos formas diferentes:

és-laal-mohá-da-es-é-lla

és-laal-mo-há-da-es-é-lla 
La primera de las opciones, con sinéresis en la palabra almohada, conserva las siete sílabas pero exige una lectura poco natural. Podría pensarse que la tendencia del habla hispanoamericana a la conversión de hiatos en diptongos facilitaría una escansión de ese tipo; sin embargo, en este poema, la palabra almohada aparece en dos versos (en uno al final y en otro al principio) y en ambas ocasiones se considera una palabra tetrasílaba («encontrar la almohada» y «almohadas sin cuento»). Por lo tanto, se descarta esta opción.

La segunda, por el contrario, introduce un verso octosílabo en una serie de versos heptasilábicos. De cualquier forma, no se produce una ruptura métrica, sino más bien una pausa, una interrupción del ritmo dominante para añadir matices nuevos que maridan bien con el resto de los versos. ¿Podría pensarse, tal vez, que este verso no desentona, rítmicamente, en el poema porque la pausa permite una lectura del verso como la unión de un pentasílabo y un trisílabo?

\section{Versos de más de doce sílabas. La barra como cesura}

En El amor, las mujeres y la vida solo hay un poema donde se emplean, mayoritariamente, los versos alejandrinos y donde se utiliza la barra. Se trata del poema «Trueque» (p. 178):

Me das tu cuerpo patria y yo te doy mi río tú noches de tu aroma / yo mis viejos acechos tú sangre de tus labios / yo manos de alfarero tú el césped de tu vértice / yo mi pobre ciprés

me das tu corazón ese verdugo y yo te doy mi calma esa mentira tú el vuelo de tus ojos / yo mi raíz al sol tú la piel de tu tacto / yo mi tacto en tu piel

me das tu amanecida y yo te doy mi ángelus tú me abres tus enigmas / yo te encierro en mi azar me expulsas de tu olvido / yo nunca te he olvidado te vas te vas te vienes / me voy me voy te espero.

La estructura claramente bimembre, en la que se contraponen el tú y el yo, se apoya en varios recursos para la orientación de la 
lectura del poema. La barra delimita el trueque de vidas, lo que ofrece el tú y lo que entrega el yo, en cada uno de los versos alejandrinos donde el nexo copulativo no está presente para marcar con claridad la división. El verso primero y el noveno, donde el nexo sí está presente, Benedetti omite la barra porque la bimembración es evidente. El quinto y sexto verso, que son endecasílabos, también van unidos, sintácticamente, mediante el nexo copulativo. Por lo tanto, la barra es utilizada aquí para establecer un límite sintáctico y métrico, al mismo tiempo, es decir, la barra marca la cesura.

El uso de la barra se hace más necesario en el único verso de más de catorce sílabas del libro donde Benedetti emplea este signo: «de pies oscuros en el barro / de caminos de irse». Este verso tiene dieciséis sílabas y varias posibles realizaciones. Se exige una lectura atenta para mantener el ritmo del poema «Bellas pero» (p. 162). Como ya se ha dicho, los versos largos, o aparentemente libres, pueden, a veces, reducirse a versos creados a partir de la unión de versos tradicionales. En este caso, Benedetti pretende que el lector no tenga que hacer un ejercicio métrico y se deje guiar por la cesura que en el poema marca el autor, reforzada, también, por el paralelismo sintáctico. El verso de dieciséis sílabas queda convertido, por lo tanto, en la unión de un eneasílabo y un heptasílabo que casan bien con el ritmo endecasilábico predominante en el poema. Al mismo tiempo, la barra demarca los sintagmas que desempeñan la misma función.

\section{Versos de entre nueve y once sílabas}

\subsection{La barra como signo de puntuación}

La barra en este tipo de versos desempeña las funciones de las que ya se ha hablado al referirnos a los versos de arte menor. Así, la barra equivale a un punto en diferentes poemas, como, por ejemplo, en «Medios de comunicación» (p. 129):

No es preciso que sea mensajera /

la paloma sencilla en tu ventana

te informa que el dolor

empieza a columpiarse en el olvido 
En otros casos, equivale a una coma, aunque este extremo merece un comentario más detenido. En todos los casos en los que Benedetti emplea la barra como pausa prosódica en los versos endecasílabos, suele aislar un heptasílabo: unas veces al principio del verso y otras al final. Puede recordar esta disposición a la de los versos dodecasílabos formados por hemistiquios heptasilábicos y pentasilábicos $(7+5$ o 5+7); sin embargo, en los casos que se encuentran en el poemario, el cómputo silábico demuestra que, aunque aparentemente se separen dos hemistiquios, el verso conserva las once sílabas y el ritmo del endecasílabo, y no las doce sílabas del dodecasílabo.

La apariencia de dodecasílabo es más engañosa cuando el primer hemistiquio es el mayor, de siete sílabas. A continuación, se rompe la expectativa con un tretrasílabo que no mantiene el ritmo endecasilábico del dodecasílabo y que, por lo tanto, hace replantear el carácter compuesto del verso:

\author{
desmilágrate ahora / poco a poco (p. 135) \\ desde el carajo al cielo / sin escalas (p. 135) \\ por él desciende al mundo / sube al cielo (p. 138) \\ más linda todavía / te perdones (p. 141) \\ tu soledad me abruma / me alucina (p. 147)
}

Más difícil es la confusión cuando el primer hemistiquio es el menor. En lugar de tener cinco sílabas, o de situar la barra tras una sílaba acentuada, el hemistiquio tiene cuatro verso. Es un tetrasílabo y no un pentasílabo:

ya lo sabes / sin tropos ni bengalas (p. 129)

calle abajo / novada y renovada (p. 135)

La consideración de estos endecasílabos como versos compuestos originaría un sinsentido métrico. Por lo tanto, aquí $-\mathrm{y}$ teniendo en cuenta el contexto métrico donde se incluyen los versos que acaban de citarse-, la barra es simplemente la marca de una pausa y no una cesura, el equivalente a un signo de puntuación que por lo general coincide con una coma. Benedetti, situado voluntariamente al margen de las convenciones ortográficas, no rompe por completo la comunicación con el lector, 
acostumbrado a la puntuación normativa, y lo orienta sobre el lugar donde la sintaxis permite hacer una pausa, que no impide la realización unitaria como verso simple, y permite, además, conservar el sentido del verso.

El uso aparente de la barra como una cesura imposible se puede encontrar, a veces, cuando el uruguayo coloca la barra en un lugar donde provoca un desequilibrio en las partes del verso y no detrás de la séptima sílaba. Se trata del verso «y vos / con esa culpa que te hace», del poema «Mengana si te vas» (p. 141). Aquí la barra ni siquiera tiene la apariencia de ser la cesura en un verso dodecasílabo, sino que se coloca tras la segunda sílaba, de manera que podría dar la posibilidad de considerar el verso como una composición extraña entre un trisílabo y un eneasílabo. Sin embargo, basta leer el siguiente verso para comprender que la barra no actúa como la marca de una cesura, sino como un signo equivalente a una coma, donde se establece una pausa y donde se marcan los límites de una inflexión tonal encerrada entre dos pausas:

y vos / con esa culpa que te hace más linda todavía / te perdones

\subsection{La barra como marca de dialefa}

Del mismo modo que en los versos de arte menor, en los versos de más de 8 sílabas, se usa la barra para señalar la existencia de una dialefa. Tal es el caso del verso «o nada/ hojas en el viento». Este verso se encuentra en el poema «Calle de abrazados» (p. 150) donde se alternan heptasílabos, eneasílabos y endecasílabos. En ese contexto métrico, sería absurdo pretender introducir un verso compuesto de un hemistiquio trisílabo y otro hexasílabo, ajeno al ritmo del poema. Igualmente, la dialefa que, en una lectura natural del verso, se ejecuta entre la sílaba «da» y «ho», queda destacada, señalada, gracias al empleo que Benedetti hace de la barra. 


\subsection{La barra como marca de cesura}

\subsection{1. ¿Versos eneasílabos o decasílabos compuestos?}

En el libro, tan solo hay un poema donde sería posible la consideración de un mismo verso como eneasílabo o como decasílabo compuesto por dos hemistiquios pentasilábicos. Se trata del poema «El amor es un centro» (p. 163). Escrito en estrofas de cuatro versos eneasílabos con rima, en asonante, cruzada, el poema mantiene una estructura bastante rígida que impediría interpretaciones o lecturas que se alejaran de ese modelo. Sin embargo, Benedetti emplea la barra para modificar la inercia rítmica en tres ocasiones: "cáliz y musgo / cruz y sésamo», «y mucho más / es una isla»y, por último, «una borrasca / un lago quieto».

En el primer verso, es evidente que la barra equivale a un signo de puntuación, a una pausa prosódica, y también a la intención del poeta de resaltar el carácter bimembre del verso.

Algo parecido se podría decir de la segunda muestra, donde se rompe el verso tras el adverbio «más». De esta forma los dos acentos contiguos, el de «más» y el de «es», quedan resaltados gracias a la pausa fuerte que marca la barra. Sin ese corte rítmico sería imposible que ambos acentos se conservaran. De hecho, el verso que sin la barra tendría un ritmo binario con una acento secundario en «una» (y-mú-cho-más-es-ú-na-ís-la) se transforma en un verso compuesto por dos hemistiquios pentasílabos con un ritmo mixto donde se mezcla el ritmo binario del primero, que termina en palabra aguda (y-mú-cho-más), y el ritmo mixto del segundo (és-u-na-ís-la). En este caso, por lo tanto, la barra equivale a una cesura y determina que el verso se convierta en un decasílabo y que ambos acentos contiguos, en virtud de la cesura, pertenezcan a hemistiquios diferentes y sigan manteniendo su relevancia, sin que ninguno de ellos se imponga al otro.

Igualmente, la barra equivale a una cesura en el último ejemplo: «una borrasca / un lago quieto». Al situar la barra entre las dos vocales e impedir la sinalefa, que en una realización del verso como simple sería inevitable, y para mantener el ritmo endecasilábico del poema, se impone la lectura del verso como 
la composición de los hemistiquios pentasilábicos: «ú-na-borrás-ca / un-lá-go-quié-to». La evidencia de que Benedetti quiere que el lector lea el verso como un decasílabo compuesto, y no como un eneasílabo simple, se encuentra en el hecho de que, en el mismo poema, en un verso con las mismas características que el que acaba de analizarse, no interpone la barra diagonal entre las dos vocales que constituirían una misma sílaba métrica, de forma que solo permite una lectura como verso eneasílabo. Me refiero al verso final del poema («una esperanza un fantasmita») cuya escansión métrica quedaría de la siguiente forma: ú-naespe-rán-zaun-fán-tas-mí-ta.

\subsection{2. ¿Versos endecasílabos o dodecasílabos compuestos del tipo $7+5$ o 5+7?}

Para analizar los versos que pueden tener una lectura como endecasílabos o como dodecasílabos, hay que tener en cuenta las mismas circunstancias que para el análisis de los eneasílabos; es decir, debe prestarse atención al lugar en que se ubica la barra, considerar que, solo cuando se sitúa tras una palabra aguda o entre dos sílabas que deberían formar una sola en virtud de la sinalefa, es posible la transformación del verso simple en un verso compuesto.

En el poema «Bébete un tentempié» (p. 135), se puede encontrar, en un contexto de versos endecasílabos, dos versos en los que Benedetti sitúa, tras una palabra aguda, la barra diagonal:

sobremuriente no / sobreviviente

bebe otro tentempié / por si las moscas

En ambos casos, el verso resultante estaría formado por un hemistiquio de siete sílabas y otro de cinco, de manera que, en lugar de considerarlos versos de once sílabas, el lector, arrastrado, por una parte, por el sentido del verso y, por otra, por la tendencia a realizar la pausa que marca la barra, termina convirtiendo el verso en un dodecasílabo. No debe olvidarse que, en este mismo poema, Benedetti emplea la barra como delimitador sintáctico, equivalente a una coma. La diferencia con esos versos es que, en este caso, el hecho de colocar la barra detrás 
de una palabra aguda, permite que el ritmo se vea alterado y el verso transformado.

Lo mismo ocurre en el poema «Utopías», ya citado, donde la barra, además de marcar una pausa sintáctica, funciona como la cesura que provoca que el final del hemistiquio sufra los mismos fenómenos métricos en relación con el cómputo silábico que un final de verso. Así, al encontrarse la barra detrás de una palabra aguda, debe entenderse que se trata de un primer hemistiquio heptasilábico y un hemistiquio final pentasilábico. Los versos son los siguientes: "cómo voy a creer / dijo el fulano», que se repite cuatro veces a lo largo del poema, y «cómo voy a creer / mengana austral». Efectivamente, la barra aísla la aclaración del primer verso, que debería ir entre guiones si se emplearan los signos ortográficos, y el vocativo del segundo, que debería emplear las comas. Eso tiene repercusiones métricas porque la barra funciona como una cesura.

En estos casos comentados, la barra se sitúa detrás de una palabra aguda. En los casos que se verán a continuación, Benedetti sitúa la barra entre dos vocales que deberían formar una misma sílaba, de manera que la barra sirve para señalar la dialefa y, al mismo tiempo, transforma el endecasílabo en un verso compuesto. Los versos son «soñándote despierto / es una noria», del poema «Soneto kitsch a una mengana» (p. 143); «afilá tu delirio / armá tu sueño» y «recuperá tu cuerpo / hacelo mío», del poema «Maravilla» (p. 149); «y el otro mundo / el que solloza apenas», del poema «Luna de idilio» (p. 157); «y el vértice de musgo/ el bienvenido» del poema ya citado «Bellas pero». En todos estos versos, la barra marca la dialefa y funciona como cesura, transformando no solo el endecasílabo en un dodecasílabo compuesto, sino modificando el ritmo del verso.

Así, el pentámetro yámbico «so-ñán-do-té-des-piér-toes-úna-nó-ria» se transforma en un verso compuesto de la siguiente forma: «so-ñán-do-té-des-piér-to / és-u-na-nó-ria». Debe tenerse en cuenta que este verso se inscribe en un soneto canónico donde se respetan las rimas clásicas, si bien existe una asonancia entre la rima de los cuartetos y la de los tercetos que, además del tono del poema, convierten el soneto en un ejercicio kitsch, tal como indica el título. Por esa razón, el lector tiende a leer el verso como 
un endecasílabo y el autor, que en la lectura pública de este poema elige la segunda opción, lo refrena. Se permitiría pues, una doble lectura: la lectura impuesta por la línea del verso -endecasílabo, entonces- y la lectura impuesta por la barra -dodecasílabo-.

En este sentido, y a propósito de la obra Carta a mi madre, la profesora María Victoria Utrera Torremocha sostiene que el empleo que hace Juan Gelman de la barra, lejos de romper el ritmo, como propone parte de la crítica, ordena métricamente el texto, de manera que el lector puede decantarse por una lectura que se ciña a la línea versal o por una lectura que atienda a los cortes impuestos por las barras:

Esta doble presentación -barra y línea- obligaría a una lectura paralela del texto: de un ritmo más libre, encabalgado y tenso, que favorecen la línea y los encabalgamientos, y de un ritmo más cadencioso que la barra marca. Este último es el ritmo que se impone de forma natural en la lectura. Es también el que Gelman sigue en la lectura pública de sus textos ${ }^{22}$.

En efecto, la poesía conversacional que practica Benedetti hace pensar que el poeta uruguayo también prefiere una lectura que preste atención a las pausas que fijan las barras, si bien la ruptura con el verso tradicional o la exigencia de una lectura paralela, como señala la profesora Utrera, no son tan intensas como en el caso de Carta a su madre de Juan Gelman.

Igualmente, el poema «Maravilla» se compone de tres cuartetos de versos endecasílabos con rimas abrazadas. Benedetti usa la barra para ofrecer al lector la doble posibilidad de seguir la lectura canónica de los versos o aquella que se acerca más a la lectura espontánea y coloquial del verso. Importante es señalar que sea cual sea la opción que elija el lector, el ritmo del verso, y del poema, sigue provocando el mismo efecto eufónico.

Se debe recordar lo que, a propósito de las características de la poética coloquial y de la poesía de Benedetti, señala Alemany Bay. Según ella, la colaboración entre autor y lector es mucho más estrecha que en la poesía tradicional y la libertad que el autor concede al lector, mucho mayor:

${ }^{22}$ Utrera Torremocha, María Victoria: «Carta a mi madre de Juan Gelman». Rhythmica. Revista española de Métrica Comparada, 2014, XII, p. 205. 
Las consecuencias de este primer efecto [la supresión de los signos de puntuación] tienen su plasmación en que tanto el autor, a la hora de la composición, como después el lector al hacer efectiva la obra literaria, colaboran o participan (no olvidemos que los poetas coloquiales son partidarios de la intervención activa del lector en el poema) en la construcción de la frase y en el ritmo de la composición. De este modo, algunos lectores, según su modo, agrado y costumbre, ampliarán o acortarán los periodos oracionales, apropiándose del poema y dándole la intensificación que ellos consideren acorde con el contenido. La capacidad de intervención de quien lee los versos es mucho mayor que en los poemas tradicionales ${ }^{23}$.

A diferencia de los ejemplos anteriores, «Luna de idilio» $\mathrm{y}$ «Bellas pero», escritos en versos de ritmo endecasilábico, carecen de la rigidez estrófica del soneto y de los cuartetos. Aquí, el lector opta por la lectura que marca Benedetti, aquella que considera el verso como un dodecasílabo compuesto por dos hemistiquios.

\section{Versos con dos barras}

El objetivo último de Benedetti al emplear la barra es establecer una comunicación con el lector, de manera que, al margen de los signos de puntuación convencionales, que pueden constreñir la lengua coloquial que el uruguayo quiere imprimir en sus poemas, la barra funciona como elemento orientador en la lectura de sus versos. Según el propio Benedetti, el lector, en esta corriente poética, ha pasado a formar parte de la creación literaria, de la ecuación poética ${ }^{24}$.

De esta forma, en El amor, las mujeres y la vida encontramos cuatro endecasílabos, uno de ellos de gaita gallega, donde se emplea dos veces la barra. En todos ellos, la barra funciona como un elemento para señalar la pausa sintáctica: el verso «grillos / calandrias / cachorros de puma», del poema «Onfálica» (p. 138); el verso «yo / tu fulano / no me mataré», del poema «Mengana si

\footnotetext{
${ }^{23}$ Alemany Bay, Carmen: Poética coloquial hispanoamericana, cit., p. 128.

24 «Es obvio que la poesía conversacional reclama o presupone un interlocutor, y el lector, al sentirse aludido, responde a ese reclamo. Tal es, después de todo, el gran avance experimental de esta tendencia: la comparecencia del lector como un nuevo dato de la ecuación poética» (BENEDETTI, Mario: «La realidad y la palabra», en El ejercicio del criterio. Madrid: Alfaguara, 1995, p. 123).
} 
te vas» (p. 141); el verso «yo / fulano de mí / llevo conmigo» y el verso «y de todo el amor / tu amor / mengana», del poema ya citado «Soneto Kitsch a una mengana».

Más importante que estos, y en relación con la doble lectura que permiten algunos versos, es el alejandrino «entre tú y yo / mengana mía / se levantaba», del poema «Epigrama con muro» (p. 145). Señala Esteban Torre al hablar de los versos alejandrinos algunos fenómenos que atañen a las peculiaridades métricas de este tipo de verso. Se refiere el profesor Torre al llamado alejandrino ternario, que dividiría el verso en tres partes, siendo «el resultado de una lectura inconsecuente con las convenciones de la métrica española. El alejandrino castellano es siempre un verso compuesto de $\left\langle 7+7 »\right.$ sílabas ${ }^{25}$. El verso de Benedetti no responde a las dificultades que pueden surgir en la escansión métrica para considerar el verso como la suma de tres partes, puesto que permite hacer una cesura evidente, sin problemas, después de la séptima sílaba, situada tras la palabra «mengana». Sin embargo, Benedetti prefiere que el lector deseche la lectura clásica del alejandrino y opte por una lectura que estructure el verso de manera ternaria. Así, frente a la escansión normativa de «en-tre-túy-yo-men-ga-na / mí-a-se-le-van-ta-ba», Benedetti empuja al lector a hacer una lectura tripartita del verso, más próxima a una realización coloquial.

\section{Conclusión}

En definitiva, la antología temática El amor, las mujeres y la vida muestra la evolución poética de Benedetti desde los primeros poemas de tema amoroso que se recogen, donde tiende a la introducción de versos arrítmicos en series de ritmo generalmente endecasilábico, y donde se mantienen los signos de puntuación, hasta los últimos poemas del libro, donde, después de haber suprimido los signos de puntuación, mantiene la comunicación métrica y rítmica con el lector gracias al empleo de un ritmo mucho más regular en los poemas y del uso de las barras, que sirven siempre para señalar, en los versos, un momento de pausa, aunque no siempre supone la conversión del verso en

${ }^{25}$ Torre, Esteban: Métrica española..., cit., p. 88. 
la suma de dos hemistiquios, es decir, aunque no siempre funcionan como una cesura.

\section{Bibliografía utilizada}

ALBURQUERQUE, Luis: «El instante del instinto: los haikus eróticos de Mario Benedetti», en Pilar Caballero-Alías, Félix Ernesto Chávez y Blanca Ripoll Sintes (eds.): Del verbo al espejo. Reflejos y miradas de la literatura hispánica. Barcelona: PPU, 2011, pp. 409-421.

ALEMANY BAY, Carmen: Mario Benedetti. Madrid: Eneida, 2000.

- Poética coloquial hispanoamericana. Alicante: Universidad, 1997.

ALEMANY BAY, Carmen: MATAIX, Remedios y ROVIRA, José Carlos: Mario Benedetti: Inventario cómplice. Alicante: Universidad, 1998.

BENEDETTI, Mario: El amor, las mujeres y la vida. Poemas de amor. Madrid: Visor Libros, 2007.

- El ejercicio del criterio. Madrid: Alfaguara, 1995.

CANFIELD, Martha: «Mario Benedetti: la sencilla complejidad de un poeta entrañable». Cuadernos de Literatura, enero-junio de 2013, XVII, 33, pp. 332-354.

CERNUDA, Luis: Las Nubes. Desolación de la Quimera. Madrid: Cátedra, 1999.

DOMÍNGUEZ CAPARRÓS, José: Métrica y Poética. Bases para la fundamentación de la métrica en la teoría literaria moderna. Madrid: UNED, 2010.

IBÁNEZ QUINTANA, Jaime: La obra poética de Mario Benedetti (19481985). Tesis doctoral. Servicio de Publicaciones de la Universidad de Burgos, 2004.

JAKOBSON, Roman: Lingüistica y poética. Madrid: Cátedra, 1983.

JAURALDE POU, Pablo, VARELA, Elena y MOÍNO, Pablo: Manual de métrica española. Madrid: Castalia, 2005.

MÁRQUEZ GUERRERO, Miguel Ángel: «Endecasílabos con acentos en $6^{\mathrm{a}}$ y $7^{\mathrm{a}}$ sílabas». Rhythmica. Revista española de Métrica Comparada, 2012, X, pp. 115-132.

PARAISO, Isabel: La métrica española en su contexto románico. Madrid: Arco/Libros, 2000.

PÉREZ AZAÚSTRE, Joaquín: Vida y leyenda del jinete eléctrico. Madrid: Visor Libros, 2013.

RAE: Ortografia de la Lengua española: Madrid: Espasa Calpe, 2010.

TORRE, Esteban: «¿Acentos contiguos en el verso español?». Rhythmica. Revista española de Métrica Comparada, 2014, XII, pp. 173-194.

- Métrica española comparada. Sevilla: Universidad, 2000.

UTRERA TORREMOCHA, María Victoria: «Carta a mi madre de Juan Gelman». Rhythmica. Revista española de Métrica Comparada, 2014, XII, pp. 195-209. 